\title{
US panel firms up views on embryo research
}

Washington. An advisory panel to the director of the US National Institutes of Health (NIH) is likely to recommend approval for experiments on human embryos up to the fourteenth day after fertilization.

It is also expected to back the approval under certain circumstances of the deliberate creation of embryos for research purposes, but to defer a recommendation on the use of oocytes from fetuses until the issues raised have been studied in more detail.

At its fifth - and probably final meeting last month, the NIH's Human Embryo Research Panel fleshed out its proposed new guidelines governing the use of human embryos in federally funded research.

The use of federal funds for such research became possible only last June, when Congress cancelled a requirement for all federally funded in vitro fertilization (IVF) research to be reviewed by an ethics advisory board. Because of links between the research and the abortion debate, the board ceased to function during the Reagan and Bush administrations, leading to a de facto ban on the use of federal funds for such research.

The panel is due to deliver its report to the NIH director, Harold Varmus in September for consideration by his advisory committee later this year. It was asked to identify areas of research considered acceptable for funding, those that are more troublesome from an ethical and moral standpoint and therefore warrant additional review, and those considered wholly unacceptable for federal support.

On the basis of a series of straw polls at the meeting, and with its public deliberations now over, the panel seems likely to recommend that all proposals falling within the 'acceptable' category be subject to some form of national review by an ad hoc body. This intentionally vague recommendation leaves room for Varmus to decide whether such a body would have primarily a monitoring or a 'gatekeeping' function.

The panel is also likely to recommend approval of the creation of embryos expressly for research purposes -- rather than limiting research to 'spare' embryos from
IVF programmes - either for fertilization studies, for use as controls, or where there is a compelling scientific need. But it voted to prohibit the payment of donors, and the use of gametes and/or embryos without the donors' consent.

The panel voted to allow the development of embryonic stem cell lines by a small margin, after hearing of the scientific potential of this work.

In line with countries such as Australia, Canada, Sweden and the United Kingdom, the panel recommended a 14-day limit on human embryo research after fertilization. This is the point at which the primitive streak can be identified in vivo, and some consider an individual's 'identity' is established.

The panel seems likely to side-step the controversial issue of whether to allow fetal ovaries to be used as a source of oocytes for the creation of research embryos, pending a more extensive review of the ethical issues.

It is also likely to propose further review on the cloning of human preimplantation embryos by either separating blastomeres or splitting blastocysts (twinning), and on the use of embryos for research after the appearance of the primitive streak, but before closure of the neural tube.

Areas expected to be declared off-limits include the creation of chimaeras, crossspecies fertilization (except to test the viability of human sperm), the implantation of parthenogenetically activated human oocytes and the use of preimplantation genetic diagnosis for sex selection (except to identify sex-linked diseases).

The panel's activities have not gone unnoticed by 'pro-life' groups, or by their congressional supporters. The International Foundation for Genetic Research/Michael Fund of Pittsburgh, Pennsylvania, for example, has filed a lawsuit against Donna Shalala, the health secretary, Varmus and all 19 panel members, attempting to halt the panel's deliberations and shift the debate from NIH to Congress.

And in a letter sent in mid-June to Varmus, co-signed by 34 mainly Republican mem-

\section{Rees appointed Astronomer Royal}

London. The Royal Society announced last week that Sir Martin Rees (right) will succeed Professor Arnold Wolfendale as Astronomer Royal, a largely honorary post created in the seventeenth century and combined up to 1971 with the directorship of the Royal Greenwich Observatory. Rees is Royal Society Professor at the Institute of Astronomy in Cambridge. He takes up the post in January, and is also next year's president of the British Association for the Advancement of Science. The Royal Society has welcomed Rees's appointment, claiming that he will be "well able to act as a spokesman for the astronomical community" in Britain.

bers of the House of Representatives, Robert Dornan (Republican, California), outlined several areas of research that he said "Congress has never discussed, and which pose grave ethical problems of their own". These, he said, include the use of oocytes from the ovaries of aborted fetuses, and the use of preimplantation diagnosis for the purposes of sex selection and genetic diagnosis.

Dornan also criticized the make-up of the panel, claiming that it was biased in favour of those with an interest in the research continuing. In reply, Varmus wrote that panel members were not picked as "proponents of specific points of view about human embryo research, and they were not asked in advance for their positions on the acceptability of this research."

Meanwhile NIH has received more than 17,000 written comments, many raising the abortion issue. Most of the letters are opposed to any form of human embryo research. But Anne Thomas, a spokeswomen for NIH, says many of the comments are not pertinent to the work of this panel.

Diane Gershon

\section{Weapons scientists back cuts in new nuclear systems}

Washington. Almost two-thirds of scientists working in weapons laboratories supported by the US Department of Energy would support a reduction in federal support for the development and testing of new nuclear weapons, according to a survey carried out on behalf of Sandia National Laboratories.

This is only slightly less than the 68 per cent of the general public which the survey, carried out by researchers at the University of New Mexico's Institute for Public Policy and the Georgia Institute of Technology, found also supported such a cutback.

Not surprisingly, however, it contrasted with the 96 per cent of members of the Union of Concerned Scientists (UCS) polled who shared this view. Similarly, while 22 per cent of the laboratories' scientists (and 31 per cent of the public) favoured cuts in existing weapons, this view was held by 75 per cent of UCS members.

Seven out of ten members of the first two groups agreed that more research is justified on increasing the safety of existing weapons, indicating general support for the type of activities that the national laboratories are keen to remain involved with.

Furthermore, a clear majority in each group (including 60 per cent of the UCS respondents) backed the idea that more money should be spent on providing training for those required to handle weapons in the nuclear arsenal. 